\title{
Política, Ciência e Mundo das Redes
}

Se Max Weber pudesse, por algum milagre, analisar as duas primeiras décadas do século XXI, ficaria intelectualmente instigado com o grau de irracionalismo da "política" contemporânea. Se essa versão encarnada do autor alemão fosse aquela associada ao romantismo e ao pessimismo cultural, ele teria a certeza de que a sua metáfora da jaula de ferro se confirmara em sua forma mais radical. A racionalidade burocrática - que, na concepção do autor, representaria uma das singularidades do capitalismo em relação aos outros sistemas - parece dividir espaço, sem contradições, com a irracionalidade. A racionalidade, forma moderna de dominação, teria produzido a reificação das relações sociais e ao desencantamento do mundo. Nesse sentido, Weber estaria de acordo com Marx de que o capitalismo moderno é um universo em que os indivíduos são dirigidos por abstrações, "em que relações impessoais e coisificadas substituem as relações pessoais de dependência e em que a acumulação do capital se torna um fim em si, amplamente irracional" (LÖWY, 2014, p. 18).

Habermas (1980) nos lembra que Weber introduziu o conceito de "racionalidade" a fim de determinar a forma da atividade econômica no capitalismo, das relações de direito privado burguesas e da dominação burocrática. A racionalização progressiva da sociedade estaria ligada a secularização e a institucionalização do progresso científico e técnico. À medida em que a técnica e a ciência penetram nas estruturas da sociedade, as antigas formas de legitimação das instituições tradicionais desmoronam. Portanto, muito distante de um Weber estrutural-funcionalista criado por Parsons, o autor alemão, por meio de sua influência no jovem Lukács, impactou na tradição da Teoria Crítica, em particular no conceito de razão instrumental.

O que assistimos hoje senão a exacerbação dessa razão instrumental, isto é, da utilização da ciência e da técnica enquanto forma de produção e reprodução da ordem do capital? Como não encontrar nas disseminadas tecnologias de informação e comunicação uma profunda abstração das relações sociais, que intensificam ainda mais aquilo que Marx chamou de fetichismo da mercadoria? A cada dia, mais e mais máquinas se autogovernam e se comunicam entre si - como é o caso, por exemplo, da "Internet das Coisas" -, aumentando o pessimismo quanto às saídas emancipatórias.

Se as utopias revolucionárias parecem terem sido temporariamente derrotadas após o fim das sociedades pós-capitalistas, no final dos anos 1980, as utopias reacionárias ganharam projeções incalculáveis, associadas ao pensamento religioso e disseminadas pelos meios informacionais-digitais. Como observa Lukács, as utopias reacionárias que visam restaurar uma condição passada, não podem deixar de ter um caráter essencialmente irracionalista. Esta visão de mundo só consegue superar as antinomias fundadas numa negação da ratio de modo pseudodialético, sofistico (LUKÁCS, 2012).

Há muito tempo que a humanidade deixou de encontrar refúgio no projeto Iluminista. Fruto da ascensão da sociedade burguesa, seu caráter progressista foi ultrapassado pela própria decadência e degeneração do capitalismo, o que confirmam as análises da Teoria Crítica. Como ressalta Habermas sobre a concepção de Marcuse acerca do caráter inconfessado da dominação política da razão instrumental, ela

(C) O(s) Autor(es). 2020 Acesso Aberto Esta obra está licenciada sob os termos da Licença Creative Commons Atribuição-NãoComercial 4.0 Internacional (https://creativecommons.org/licenses/by-nc/4.0/deed.pt_BR), que permite copiar, distribuir e reproduzir em qualquer meio, bem como adaptar, transformar e criar a partir deste material, desde que para fins não comerciais e que você forneça o devido crédito aos autores e a fonte, insira um link para a Licença Creative Commons e indique se mudanças foram feitas. 
se estende à escolha correta entre estratégias, ao emprego adequado de tecnologias e à organização de sistemas de acordo com fins (no caso, com objetivos estabelecidos em situações dadas), essa espécie de racionalidade subtrai à reflexão a contextura de interesses globais da sociedade - ao serem escolhidas as estratégias, empregadas as tecnologias e organizados os sistemas -, furtando-a a uma reconstrução racional (HABERMAS, 1980, p. 311).

O que surpreende na sociedade contemporânea - e este é um desafio instigante para as ciências sociais - é que esta irracionalidade se proliferou e ganhou dimensões até então incalculáveis com a difusão das novas tecnologias de informação e comunicação e com o mais moderno maquinário automatizado implementado no mundo produtivo. Antes da pandemia causada pela Covid-19, alguns autores e personalidades empresariais anunciavam que a revolução tecnológica em curso nos levaria a um admirável mundo novo em que o progresso técnico traria a emancipação das tarefas mais árduas nas esferas da produção e da reprodução social (SCHWAB, 2017). Nada mais falacioso que esta velha promessa burguesa. A própria crise sanitária - que tem dimensões sociais, políticas e econômicas - desnudou as contradições mais latentes do capital.

As plataformas digitais, fruto direto dessas transformações tecnológicas, tornaram-se poderosos instrumentos de relações econômicas, sociais e políticas. Após algumas décadas de disputas desenfreadas entre várias empresas e "empresários inovadores", o setor se monopolizou. As duas mais importantes são o Facebook e o Google. A primeira é a maior rede social do mundo, alcançando 2,3 bilhões de pessoas, e controla não apenas o aplicativo de mesmo nome como as outras três principais redes sociais (FB Messenger, Whatsapp e Instagram). A segunda empresa é o mais importante mecanismo de busca usado no planeta (com exceção da China) e é dona de um sistema operacional (Android), do Youtube e do Gmail. Assim, pode-se definir que:

as plataformas digitais são sistemas tecnológicos que funcionam como mediadores ativos de interações, comunicações e transações entre indivíduos e organizações operando sobre uma base tecnológica digital conectada, especialmente no âmbito da Internet, provendo serviços calcados nessas conexões, fortemente lastreados na coleta e processamento de dados e marcados por efeitos de rede (VALENTE, 2019, p. 170).

O presente número da Revista Katálysis está voltado para uma reflexão acerca das relações entre Política, Ciência e o Mundo das Redes. Ele reúne artigos do Serviço Social e áreas afins sobre o papel do uso da informação, do trabalho com dados, da utilização de sistemas eletrônicos e redes digitais na intervenção profissional e na produção de conhecimentos. Também problematiza os novos formatos e possibilidades de participação democrática, controle e acesso à informação pública, compreendendo as redes e mídias sociais tanto como instrumentos de reificação e dominação quanto potenciais de articulação e organização de movimentos sociais.

O dossiê contém artigos resultados de pesquisas teóricas e empíricas. No primeiro caso, o artigo intitulado Lukács: o "falso socialmente necessário" de Lessa, apresenta-nos a importância do conceito de "falso socialmente necessário" de Lukács com o objetivo de contribuir para as investigações sobre a força política atual de ideias e concepções "fantasticamente inverídicas". Hermeto, em Rumo a uma crítica sobre propriedade intelectual, inspirado também em Lukács e Hegel, apresenta-nos uma crítica imanente à categoria de propriedade intelectual desde a perspectiva do trabalho e do desenvolvimento cultural do pensamento humano com o objetivo de compreender a essência das relações mundiais digitais e virtuais e seus resultados.

Três artigos dialogam e abordam temas como a política, a biopolítica, o discurso do ódio e o neoliberalismo. Veiga Dias e Amaral, em Controle de dados e manipulação da vida pós-democrática, entendem a tecnologia como parte das relações de controle biopolítico e, nesse sentido, objetivam entender como o atual projeto de controle neoliberal afeta a sociedade brasileira enquanto uma democracia recente. Oliveira e Cerrat, em Pobreza como malware: aplicativos e retração dos direitos sociais, apontam as relações dos aplicativos com a crise econômica de 2008 e a retração dos sistemas de proteção social sob a influência da racionalidade neoliberal. Por fim, Ódio e intolerância nas redes sociais digitais de Quadrado e Ferreira, complementam a discussão deste bloco analisando os discursos de ódio e a intolerância nas redes sociais digitais. Esses três artigos se preocupam em compreender o quanto a democracia liberal brasileira está ameaçada por essas tecnologias e políticas.

Um outro conjunto de textos desse dossiê enfrenta o debate sobre gênero, feminismo e mundo digital. Oliveira, Silva e Silveira, em As mulheres, os feminismos e as TICs, problematizam a utilização da internet por grupos oprimidos e marginalizados socialmente, em particular o movimento feminista. Castro, no artigo As lutas feministas e sua articulação pelas mídias digitais: percepções críticas, ressalta as mídias digitais como instrumento das lutas feministas, apontando que elas ampliam tanto o alcance de seus discursos quanto a intensidade das reações contrárias. Silva e Souza, em Redes sociais e ativismo materno: 
desafios entre estudantes de uma universidade pública, apresentam os resultados de uma pesquisa empírica sobre as condições de permanência de estudantes mães em uma universidade pública federal. Por fim, Ramires, Mulheres jornalistas esportivas e mercado de trabalho: quem (não) as deixa trabalhar?, analisa o discurso de mulheres jornalistas esportivas brasileira que se reuniram para denunciar situações de assédio e violência sofridas no trabalho.

Outros quatros artigos compõe o Dossiê. Orth e Soares, em Empresa Brasil de Comunicação (EBC): a comunicação pública em declínio, analisam o processo de desmantelamento da Empresa Brasileira de Comunicação. No artigo intitulado Influência da participação popular em interface digital na proposição de leis estaduais, Ladinho Junior e Dufloth apresentam os resultados de pesquisa sobre os canais de "eparticipação" do portal da Assembleia Legislativa de Minas Gerais e da Câmara de Deputados e do Senado Federal, buscando compreender a quanto os cidadãos comuns influenciam a proposição de leis com envio de sugestões nessas interfaces digitais. Schuartz e Sarmento analisam os impactos da tecnologia de informação e comunicação na educação. Por fim, Raposo, em A escravidão digital e a superexploração do trabalho: consequências para a classe trabalhadora, aborda o tema da precarização do trabalho e as plataformas digitais, dando especial destaque ao setor de serviços, especificamente o trabalho monitorado e controlado por novos dispositivos tecnológicos e de rede.

O dossiê tem o mérito de pontuar e problematizar algumas questões prementes da sociedade contemporânea, articulando a relação entre política, ciência e mundo das redes. Incentivamos a todos e todas a lerem e debaterem os seus artigos ${ }^{1}$.

Ricardo Colturato Festi, Brasília, 30 de junho de 2020.

\section{Referências}

HABERMAS, J. Técnica e ciência enquanto ideologia: para os 70 anos de Hebert Marcuse, no dia 19-VII-1968. In: BENJAMIN, W.; ADORNO, T. W.; HOKHEIMER, M. (Eds.). Textos escolhidos. São Paulo: Abril, 1980. p. 343.

LÖWY, M. A jaula de aço: Max Weber e o marxismo weberiano. Tradução: Mariana Echalar. São Paulo: Boitempo, 2014.

LUKÁCS, G. Para uma ontologia do ser social I. Tradução: Carlos Nelson Coutinho; Tradução: Mario Duayer; Tradução: Nélio Schneider. São Paulo: Boitempo, 2012.

SCHWAB, K. La quatrième révolution industrielle. Malakoff: Dunod, 2017.

VALENTE, J. Tecnologia, informação e poder: das plataformas digitais online aos monopólios digitais. Tese de Doutorado - Brasília, D.F.: Universidade de Brasília, 2019.

\section{Nota}

1 Este número da Katálysis ainda contém o espaço tema livre e o espaço especial com artigos de palestrantes de dois importantes eventos científicos que ocorreram em 2019: III Seminário Nacional de Serviço Social, Trabalho e Política Social (UFSC) e Seminário Nacional sobre Trabalho na Sociedade Contemporânea (UFAL). (Nota do Editor).

\section{Ricardo Colturato Festi}

https://orcid.org/0000-0001-6360-2875

ricardo.festi@unb.br

Doutorado em Sociologia pela Universidade Estadual de Campinas (UNICAMP)

Professor Adjunto do Departamento de Sociologia da Universidade de Brasília (UnB)

\section{UnB}

Instituto de Ciências Sociais

Campus Darcy Ribeiro

Asa Norte

70910900 - Brasília, DF - Brasil 